\title{
EL HUMOR, LA IRONÍA Y EL CÓMICO: CÓDIGOS TRANSGRESORES DE LENGUAJES E IDEOLOGÍAS
}

\section{M.a Belén Hernández González}

Universidad de Murcia

«Le rire est satanique,

il est donc profondément humain»

Baudelaire (1855: 171).

\section{FUNCIÓN TRADICIONAL DE LOS GÉNEROS CÓMICOS}

Desde los orígenes de la literatura occidental, la presencia en determinadas obras de procedimientos tales como el humor o la perspectiva cómica, ha sido motivo suficiente para situar a las mismas en una tipología inferior, subordinada a otra de rango más elevado, portadora de una función heurística y ontológica. Las relaciones entre el orden moral y el estético a través de la praxis retórica clásica y medieval de 
la discretio y el decoro ${ }^{1}$ han alejado tradicionalmente a los textos humorísticos de las esferas del poder.

Así, Platón en el Filebo, donde se analiza la relación entre el placer y el bien, habla del ridículo, dentro de una discusión general sobre las afecciones del alma, donde se mezclan placer y dolor (Platón, 1992: 8893). Lo ridículo, dice la voz de Sócrates, es un vicio inherente al ser humano que tiene su origen en la ignorancia de sí mismo. Este desconocimiento ciego puede aplicarse a los bienes materiales (creerse más rico de lo que se es) y a las cualidades físicas (creerse más fuerte o bello de lo que se es), pero especialmente afecta a las cualidades del alma, y entre sus virtudes la más preciada es la del saber: se crea así una ilusión de superioridad con respecto a la realidad (Platón, 1992: 90-91).

A la ignorancia sobre sí mismo añade Platón la ausencia de poder, puesto que sólo aquellos que no son terribles y odiosos, es decir, los débiles, pueden ser objeto del ridículo. A propósito de este tema, Giulio Ferroni (1983: 21) escribe:

\begin{abstract}
Nell 'ottica del Filebo il riso non è qualcosa che corregge l'errore dell'ignoranza di sé, non è un processo con cui la sapienza possa in ogni circostanza smentire la falsa superiorità dell'ignorante ridicolo: esso appare troppo condizionato dalla forza materiale perche possa adeguatamente intervenire nel processo della verità ${ }^{2}$.
\end{abstract}

Lo ridículo está mezclado en Platón con el dolor, puesto que la risa es provocada por el placer de contemplar la ignorancia ajena, lo cual confirma su negatividad y por tanto su inutilidad pedagógica (Platón, 1992: 92-93). Otra cosa distinta es fingir ignorancia, cuando en realidad se posee la sabiduría, con el fin de desenmascarar los conceptos, como en la ironía socrática.

En la Poética de Aristóteles (1982: 67), lo ridículo se sitúa dentro de la definición de comedia, contrapuesto a la mimesis poética de las acciones nobles, que constituye los géneros de la epopeya y la trage-

\footnotetext{
1 Recordemos que el término discretio empieza a ser interpretado por Prudencio y Lactancio en el sentido de selección dirigida por la razón, que se rige por la moderación moral y se identifica con el buen sentido y el buen gusto. Análogamente, el concepto de decoro, tal y como lo explica Lausberg (1966: 374-381), incluye el término de aptum o conveniens, que se debe combinar según un criterio ético general.

2 Véase este texto para una aproximación a la línea negativa del cómico, desde la antigüedad a nuestros días. Otros estudios destacados que asumen esta perspectiva son los de Borsellino (1989), Celli (1982), English (1986).
} 
dia. Lo cómico o ridículo se configura como una imitación de figuras humanas de calidad moral inferior, la cual produciría los géneros satírico-burlescos y la comedia:

La comedia es, como hemos dicho, mimesis de hombres inferiores, pero no en todo el vicio, sino lo risible, que es parte de lo feo; pues lo risible es un defecto y una fealdad sin dolor ni daño, así, sin ir más lejos, la máscara cómica es algo feo y retorcido sin dolor.

La definición de Aristóteles, a diferencia de Platón, elimina el dolor del cómico, pero introduce su relación con lo feo y lo deforme, la cual persistirá hasta Bergson (1956: 839), que también relaciona la risa con una mecanicidad que deforma la naturaleza.

La poesía cómica, despojada de los valores religiosos y míticos de la poesía trágica, ha tenido a lo largo de la tradición una función exclusivamente lúdica y por tanto carente de aureola, en el sentido que da al término Walter Benjamin (1980: 85-120). El pensamiento clasicista ha desvalorizado la cultura del cómico porque estaba ligada a los aspectos más bajos del hombre; así no se ha ocupado de realizar una estética del mismo, aunque tampoco ha podido excluirlo de la cultura dominante, ya que éste forma parte de la esencia humana ${ }^{3}$. La ilegitimidad del cómico frente a la alta cultura, a la vez que ésta lo aceptaba transitoriamente en circunstancias particulares, ha dado lugar a cierta ambigüedad teórica con respecto a las relaciones del cómico con el sufrimiento, el placer, lo feo y lo ridículo ${ }^{4}$.

Pedro Aullón de Haro (1991: 202) resume en un breve texto la situación del cómico en la tradición:

El pensamiento clasicista nunca alcanzó a elaborar una teoría estética del Humor propiamente dicho, fuera de los límites del ingenio barroco [...] No

3 Cfr. la frase citada de Baudelaire y la teoría del homo ludens popularizada por Huizinga (1968: 7-8), que analiza el concepto de homo sapiens dieciochesco, desglosándolo en dos métodos de actuación de la inteligencia humana: la fabricación y el juego. Por tanto, añade dos funciones esenciales que nos distinguen, la de homo faber y la de homo ludens.

4 Giulio Ferroni (1983: 30-44) se ocupa de las implicaciones socio-políticas que se ocultan bajo esta ausencia teórica de la tradición; la interpretación negativa del cómico de Ferroni acepta las teorías carnavalescas bachtinianas, aunque critica el abuso e instrumentalización de las mismas por parte de la crítica literaria de los setenta, especialmente en Italia, donde la obra del pensador soviético ha sido muy difundida. 
podía ser de otro modo dentro de una cosmovisión dominante en la cual la indesglosable asociación estético-ética de lo Bello y lo Bueno como el primero de los bienes cancelaba el espacio artístico para una posible representación de la fealdad en la gran poesía.

Efectivamente, sólo durante el periodo barroco se manifiesta de forma ostensible este dualismo entre lo serio y lo cómico. En Goya o en Cervantes encontramos la expresión más genial de la ambigüedad mencionada; pero ambos son, no casualmente, figuras representativas de una sociedad en crisis, en la cual toman cuerpo las lógicas subalternas del caos, la desarmonía y el laberinto. Por ello el pensamiento barroco constituye el más claro antecedente de la cultura moderna 5 .

\section{LAS POÉTICAS DEL HUMOR EN LA TEORÍA ESTÉTICA MODERNA}

Hasta finales del siglo XIX y principios del XX las investigaciones filosóficas o teóricas sobre la función del humor en la vida y el arte eran prácticamente inexistentes. Sin embargo, hacia el 1900, con el desarrollo de las disciplinas psicológicas, un nutrido grupo de pensadores europeos dirigió su atención al tema, mostrando nuevas perspectivas que modificaban sustancialmente la valoración precedente del cómico y que han determinado la consideración del mismo durante el presente siglo. Entre los filosofos y escritores que publicaron sobre ello, destacan Th. Vischer (Auch Einer, 1879), K. Fischer (Ueber den Witz, 1889), Th. Lipps (Komik und Humor, 1898), S. Freud (Der Witz und seine beziehung zum Unbewussten, 1905), L. Pirandello ( $L^{\prime}$ Umorismo, 1908) etc. En ellos se deja sentir la influencia de las obras de Jean Paul (Richter) y de Baudelaire, por mencionar a dos autores representativos de una ruptura con la tradición literaria anterior que se ocuparon de la función del humor en el arte. Finalmente, de forma más universal, el Zarathustra de Nietzsche (1982: 166-172) se define a sí mismo como aquel que se ríe de la verdad, y se establece así una relación determinante entre la modernidad y la risa que evi-

5 Para una aproximación a la función transgresiva de la literatura barroca, véase El Outmani (1995). 
dencia la decisiva fractura estética que se está produciendo en la época.

La transformación de dos conceptos fundamentales de la teoría estética precedente, la belleza y la verdad, provoca un cambio en la función de lo cómico. Hasta entonces, la unión entre estética y ética no se había visto interrumpida de forma consciente y generalizada. Esta circunstancia permite distinguir por primera vez entre un uso programático del humor desde una perspectiva estética y el contenido más o menos grotesco de las obras literarias, reflejo de la faceta cómica del género humano. Buen ejemplo de ello es la reflexión de Pirandello (1989: 68-128) en su ensayo sobre la literatura humorística, en el cual traza una historia de la literatura marginal, escogiendo solamente las obras escritas con la óptica del humor, que se distinguen por acoger la perspectiva trágica y la cómica superando a ambas en la valoración final del autor.

La posición marginal del cómico en la tradición es paralela a su instalación en las clases populares, como ha estudiado Mijail Bachtin (1974), lo cual hace que esté aún más desprestigiado entre las clases nobles. Sin embargo, la vía carnavalesca, que es la que se manifiesta de forma más violenta contra la clase dominante, y por tanto la más subversiva y liberadora, se desvía de la línea humorística que nos interesa estudiar aquí. Reproduzco una página de Bachtin (1974: 17) que especifica esta diferencia claramente y que me parece importante para deslindar la materia que se propone:

La risa carnavalesca es ante todo patrimonio del pueblo; todos ríen, la risa es general; en segundo lugar es universal, contiene todas las cosas y la gente (incluso las que participan en el carnaval), el mundo entero parece cómico y es percibido y considerado en un aspecto jocoso, en su alegre relativismo; por último, esta risa es ambivalente: alegre y llena de alborozo, pero al mismo tiempo burlona y sarcástica, niega y afirma, amortaja y resucita a la vez.

Una importante cualidad de la risa en la fiesta popular es que escarnece a los mismos burladores. El pueblo no se excluye a sí mismo del mundo en evolución. También él se siente incompleto; también él renace y se renueva con la muerte.

Ésta es una de las diferencias esenciales que separan la risa festiva popular de la risa puramente satírica de la época moderna. El autor satírico que sólo emplea el humor negativo, se coloca fuera del objeto aludido y se le opone, lo cual destruye la integridad del aspecto cómico del mundo por lo que la risa negativa se convierte en un fenómeno particular. Por el contrario, la risa popular ambivalente expresa una opinión sobre el mundo en plena evolución, en el que están incluidos los que ríen. 
Observamos que lo carnavalesco es colectivo y coral, puesto que es herencia de las formas de expresión populares primitivas, mientras que a la risa moderna se le atribuyen sólo valores negativos, de desarmonía y destrucción particulares. Es decir, que aparece una primera distinción entre el cómico universal y el humor individual. Sirva esta precisión como marco general para situar el pensamiento sobre el cómico de las nuevas poéticas dentro de la línea de humor moderno. Aunque tendremos que volver a plantear más adelante la cuestión de que esta vía excluye la autocomicidad ${ }^{6}$.

Evidentemente, para que se produzca el efecto cómico, como dice Bergson (1956: 821), es necesario compartir la burla:

\begin{abstract}
No saborearíamos lo cómico si nos sintiésemos aislados. Diríase que la risa necesita un eco [...] Nuestra risa es siempre la risa de un grupo [...] por muy espontánea que se la crea, siempre oculta un prejuicio de asociación y hasta de complicidad con otros rientes efectivos o imaginarios.
\end{abstract}

La risa, según Bergson, debe integrarse en un medio natural determinado, y éste necesariamente se encuentra en la sociedad, por ello tiene una significación eminentemente social. Esta conclusión se deduce de dos premisas fundamentales: a) que el hombre es un ser que ríe, y b) que vive en sociedad. La diferencia entre lo cómico y lo trágico estriba en una necesaria complicidad con el receptor. Obsérvese cómo Bergson se inscribe aún en la consideración moralista de la risa que hemos señalado, ya que la complicidad y la malicia son conceptos opuestos a la ingenuidad y la bondad.

Ahora bien, si la condición para que se produzca el efecto cómico es que el destinatario sea capaz de realizar una descodificación previa del mensaje, marcado con unos procedimientos especiales, entonces hay que estudiarlo como un código cuya lectura se produce en dos momentos:

6 Como puede verse, Bachtin atribuye al cómico moderno una función exclusivamente negativa, que excluye de la burla al burlador. Sin embargo, en el caso de escritores como Pirandello, el autor no se encuentra por encima del objeto humorístico, y, en consecuencia, el resultado es que produce la misma ambivalencia de risa y dolor que el carnaval.

Para una revisión de las teorías bachtinianas en el cómico moderno, véanse Huerta Calvo (1989), Bottiroli (1990: 147-165), Hutcheon (1984: 13-26) y Colaizzi (1995). 
1) El reconocimiento del efecto cómico a través de ciertas operaciones mentales individuales.

2) Una posterior contextualización social, al tiempo que se completa su función.

Ambos estadios del proceso de recepción del cómico son independientes de que éste responda a una memoria colectiva, como el carnavalesco, o a un efecto de situación.

James F. English (1986: 138) analiza estos dos momentos desde el punto de vista de la teoría de la recepción:

The sequential method of reader response criticism provides a way to separate off the comic moment from other moments in the reading experience which similarly call for the resolution of incongruities. As it affects the mental processes of the reader, therefore, the comic can be regarded as a special instance, marked by its extreme suddenness. It interrupts a developing pattern of thought and initiates an especially rapid mental reversal or rearrangement of seemingly secure textual data.

De este punto de vista teórico se puede concluir que el cómico necesita una codificación especial en función de su intención transgresiva. $\mathrm{Su}$ discurso es aparentemente incongruente, absurdo, lo cual produce en el receptor sorpresa, $y$, solamente superando el significado inicial, puede el espectador interpretar el verdadero sentido del mismo. La complicidad entre el burlador y el receptor es imprescindible para superar la primera instancia del proceso y a la vez establece un vínculo que puede ser interpretado dentro del marco social. Paralelamente, esta recodificación del sentido inicial obliga al receptor a percibir algo desde dos perspectivas incompatibles ${ }^{7}$, puesto que su estrategia es la de la desorientación, y de este modo destruye o deforma los modos habituales del pensamiento.

Efectivamente, todas las formas del cómico son en mayor o menor medida subversivas, bien porque expresen el sentir popular contra un poder dominante o las trasformaciones de un sistema en evolución o en crisis.

7 Véase la teoría de N. Borsellino (1989: 21), según la cual la risa desvela el dualismo del mundo, es decir, la presencia, junto al mundo oficial, de un segundo mundo dẻ juego y de ficción. 
Ferroni (1983: 31) describe un panorama alternativo a la cultura oficial a lo largo de la tradición, rescata los momentos en los cuales se han legitimado los discursos cómicos y los revaloriza ideológicamente:

\begin{abstract}
In queste varie direzioni, il comico ha funzionato come strumento di legittimazione ideologica, trovando agevolmente il suo posto e fornendo utili contributi nella congerie di rivendicazioni del marginale, del basso, del periferico, del minore, che sono emerse sulla scena sociale degli ultimi anni [...] Tutti gli attributi tradizionalmente negativi del comico, i suoi legami con lo sconveniente, il turpe, lo osceno, il corporeo, il basso, ecc., si sono di conseguenza presentati come modelli alternativi, espressioni di una liberazione capace di darsi attraverso la pratica ininterrotta del rovesciamento della logica del potere e del dominio.
\end{abstract}

Sin embargo, sería un error situar en el mismo plano de transgresividad a todas las formas del cómico. Según la intención y la intensidad del contraste con respecto al pensamiento lógico oficial, puede producirse una mayor o menor desacralización de las normas establecidas. Como ha resaltado Linda Hutcheon (1984: 16), existen formas transgresivas legalizadas, que incluso pueden contribuir a la consolidación de una ley, y otras que son fuerzas anárquicas y revolucionarias. La reflexión que Hutcheon aplica a la parodia puede hacerse extensiva al cómico en general; la transgresión a veces comulga con la ortodoxia al sistema, puesto que amplía la capacidad de interpretación de lo real. Así, entre un extremo y otro encontramos una amplia gama de formas cómicås que van desde una posición conservadora a otra renovadora y subversiva. El valor ideológico de cada una de ellas está ligado al mismo tiempo al tipo de cómico, es decir, a lo que Bergson (1956: 847-899) ha esquematizado en tres clases de cómico:

1. Cómico de situación: transitorio y producido por la alteración de un estado normal.

2. Cómico de carácter: permanente y producido por un defecto o una deformación de comportamiento, relacionado con la persona que lo encarna.

3. Cómico verbal: producido por la estructura de la frase o la elección de las palabras, independientemente de quien las pronuncia.

Para concluir con estas consideraciones sobre el carácter cómico en la teoría estética moderna, hay que recordar que pertenece a una cate- 
goría trasgenérica; no es en sí misma un género, sino que puede actuar sobre los tres clásicos: épico, lírico o dramático, deformando sus valores esenciales. Esto quiere decir que puede aparecer en expresiones que no se consideran burlescas, como es el caso de las tragedias de Shakespeare. Su presencia en la literatura y el arte es muy variada. Si buscamos un rasgo distintivo del cómico, no encontramos más que la risa, que no puede formalizarse en fórmulas fijas, sino que constantemente sufre modificaciones, puesto que su esencia es antiprogramática; por eso es más fácil hablar de formas cómicas que de la categoría en sí, y por tanto no es casual que exista una confusión terminológica entre los distintos vocablos, que a menudo se alternan indistintamente, aunque Borsellino (1989: 15) reconoce la legitimidad de algunos de ellos:

Il riso è una manifestazione di sovranità sugli eventi e non s'identifica necessariamente con le modalità del comico. Per questo forse è rimasta finora controversa la questione della legittimità estetica del comico, mentre sono considerate più lecite le sue determinazioni classiche di poetica $\mathrm{e}$ di retorica: ironia, parodia, satira, umorismo.

Hablaremos a continuación de algunas de estas formas, teniendo siempre como marco de referencia las características del cómico señaladas. La especial codificación cómica a la que hemos aludido obligará al receptor a una interpretación trasgenérica de acuerdo con su naturaleza oblicua y transgresiva ${ }^{8}$.

\section{HACIA UNA TEORÍA TRANSVERSAL DE LOS CÓDIGOS CóMICOS}

La fuerza transgresora de los códigos cómicos en la literatura moderna se debe en gran parte a su capacidad para penetrar y deformar

8 J. F. English (1986: 149) resalta: «This sort of oblique communication between text and reader has no place in our current modes of inquiry into the comic. But it is of the essence of the comic to enable such communication, to assist in the very processes of context-building and self-orientation by which we make and remake sense of literary text. The lauthing reader must be understood as interacting with the text in a way that is productive of textual meaning, and this will require the development of new, trans-generic approaches to the comic capable of addressing its neglected communicative function». En efecto, la aplicación de un esquema transversal para todos los géneros literarios cambia sobre todo la función del cómico en el texto literario, puesto que pasa de ser una categoría para clasificar las obras a un elemento de la retórica de la persuasión. 
cualquier categoría genérica, alterando los rasgos pertinentes de sus lenguajes respectivos y las estructuras ideológicas de sus personajes. El proceso de codificación afecta no sólo a la norma lingüística, o al contexto estilístico (Riffaterre: 1976), que genera un contraste entre el patrón linguiístico esperado y el hallado, sino también a la lógica del discurso, en tanto que el autor humorista construye el texto a partir de una realidad invertida o alterada en mayor o menor medida, lo cual provoca una interpretación oblicua entre la lógica establecida y la subversiva. Todo ello nos induce a revisar los recursos retóricos que sustentan la argumentación humorística, y a ubicar en la teoría de la persuasión (García Berrio, 1994: 218-232) las bases para una caracterización de los códigos cómicos, en lugar de distinguirlos según las clases genéricas.

El cómico literario se ha configurado en la tradición por contraste con lo trágico. Lo serio opuesto a lo ridículo ha creado una bipolaridad que se ha denominado respectivamente tragedia y comedia en la división de géneros. Atendiendo a las formas de cada una, William E. Gruber (1981: 207-227) ha observado una divergencia esencial: mientras la tragedia expresa una necesidad histórica, en la cual se resalta al hombre actuando como puede, no como quiere, la estructura de la comedia sustituye, en cambio, el proceso histórico por una decepción: los objetos se mueven en diferentes direcciones y ofrecen una alternativa al proceso histórico. Ello tiene como consecuencia que las formas de la tragedia no posean una libertad inventiva, mientras que las de la comedia sorprenden siempre las expectativas del lector, éstas son destruidas a través de una ley arbitraria que rompe la lógica causa-efecto y obliga a organizar la acción de forma anárquica (Gruber, 1981: 210):

\footnotetext{
Tragic dramatists have proved remarkably uninventive [...] The characters never possess the freedom to break free of their roles [...] Comedy, for in contrast to tragedy, which always proceeds according to some rule of finally intelligible law, comedy is anarchic in a very special sense. Broadly speaking, it has been the role of the comic hero consistently to avert tragedy by thoroughly disarranging the word he inhabits so as to place on stage an action which is not truly informed by ironic neccesity.
}

La conclusión de Gruber es que tanto la tragedia como la comedia parten de una aplicación central de la ironía, que posteriormente organiza las estructuras respectivas de ambas como formas estéticamente opuestas. 
El desarrollo de la ironía ha sido paralelo en los dos géneros, aunque el vacío teórico con respecto a los códigos cómicos ha contaminado a menudo términos como ironía, sátira, grotesco o parodia. En el ámbito de la codificación de las formas cómicas, entenderemos la ironía como procedimiento retórico orientado según una pragmática determinada 9 .

Efectivamente, entre los autores y teóricos de principios de siglo persiste la preocupación por deslindar la ironía retórica de la ironía filosófica. En la raíz de la ironía socrática puede verse un elemento ético y moral sobre el que reflexiona Frederic Guillaume Paulhan (1914: 146-147), autor que rechaza la ironía satírica y burlona por considerarla destructiva y defiende la ironía moral, que es expresión de una posición relativista ante la vida. En rigor, la perspectiva del ironista debe ser esencialemente antidoctrinal, como en el método socrático, y de ahí su dificultad, puesto que de este modo descubre las limitaciones y falsedades de los valores absolutos y la inquietante contradicción de las relaciones del hombre y el mundo.

El concepto de ironía indicado se aleja coscientemente del efecto cómico, sin embargo, hay que destacar dos aspectos comunes con los discursos trasgresivos que nos interesan:

1) La ironía es un proceso analítico.

2) La ironía es un proyecto de desmitificación.

(1) El texto irónico se aleja de la realidad mediante una premisa fingida, pero posee una función pedagógica; es un instrumento de conocimiento, y como tal es un proceso intelectual que descubre verdades que están ocultas o latentes bajo falsas apariencias. Para cumplir este proceso, es necesario que el pensamiento sea flexible, que posea una gran movilidad, lo cual es también una de las características del discurso cómico.

(2) Al mismo tiempo, el obligado relativismo del ironista, con respecto a cualquier aseveración u observación de lo real, produce

9 Para una aproximación a la ironía desde el punto de vista retórico, son fundamentales los trabajos de Knox (1961), Hutcheon (1981: 140-155), Booth (1986) y Kerbrat-Orecchioni (1980: 108-127). 
una actitud de desapasionamiento o de distancia del objeto, lo cual puede llegar a convertirse en indiferencia o cinismo en algunos casos. De cualquier manera, es claro que pretende desmitificar, puesto que la contradicción entre lo que se dice y lo que se piensa intenta desenmascarar una visión del mundo. $Y$ esto también es común al cómico, que consigue desvalorizar las lógicas instituidas.

La ironía, como es sabido, es un fenómeno complejo, y costitutivamente ambiguo, puesto que por una parte pretende crear una aproximación auténtica a la realidad y, por otra, ella misma puede sucumbir a su propio relativismo y quedar reducida a mero juego de ingenio ${ }^{10}$.

En la ironía romántica se produce la absolutización del yo a partir de la difusión de las teorías subjetivistas de Fichte y del círculo de Jena. Una de las figuras más admiradas por Ortega ${ }^{11}$, el filósofo alemán Max Scheler (1929: 76-77), que colabora en la Revista de Occidente, expresa así la importancia de la subjetividad en la estética romántica: «El hombre es el ser superior a sí mismo y al mundo. Como tal ser, es capaz de ironía y de humor —que implican siempre una elevación sobre la propia existencia». La ironía asumirá un papel central en la poesía romántica; su base teórica es la asunción de que la subjetividad humana posee capacidades trascendentales que son consecuencia de las dotes extraordinarias de la razón. Pero esta superioridad conlleva el anulamiento de las apariencias del mundo.

10 Recuérdese la aportación de Anthony A. C. Shaftesbury, que publica en 1709 Sensus communis, donde distingue una ironía defensiva de la ironía utilizada con el fin de sacar a la luz lo verdadero, superando las convenciones del discurso. Un año antes, había aparecido su Carta sobre el entusiasmo, donde anima a utilizar la ironía contra esa forma exacerbada de entusiasmo que es el fanatismo, sea religioso o político.

La ironía, en la concepción shaftesburiana, heredera, asimismo, del método socrático, revela la desarmonía de las acciones viciosas así como de los comportamientos supersticiosos o fanáticos, y es el instrumento ideal para corregir y educar al hombre en la virtud y en el equilibrio. Éste último, el equilibrio, será la clave en las teorías de Paulhan (1914: 172) y Jankélévitch (1983: 53), para superar la paradoja de la ironía que estamos viendo.

11 El propio Ortega (1993: 177-178) se ocupará del concepto de ironía en el arte moderno oponiendo racionalismo/espontaneidad: la ironía tradicional socrática (que ha sustentado una fe ciega en el racionalismo) se entiende como un alejamiento racional y abstracto de la vida, la cual tiene, sin embargo, un componente irracional ilimitado: «El hombre del presente desconfía de la razón y la juzga al través de la espontaneidad. No niega la razón, pero reprime y burla sus intenciones [...] Tal es la ironía irrespetuosa de Don Juan.» Estas ideas se repiten en otros escritos de La deshumanización del arte (Ortega, 1993: 382). 
La ironía indica la falta de adecuación entre el artista creador como sujeto absoluto, por una parte, y la obra de arte junto al mundo, en cuanto elementos relativos, por otra. Esta contradicción ha sido analizada por D. C. Muecke (1969: 191) teniendo en cuenta los factores filosóficos de intelectualidad y autoconsciencia:

\begin{abstract}
The compost which the Romantic Irony grew may be summary characterized as a combination of an intelectual ferment, a dynamic Lebensanschauung, a heightened self-awareness (from the conjuction of these last two emerges the peculiarly German emphasis upon the will), and a recognition and acceptance both or the complexity and contradictionness of the world. Implicit in all this are both the irony of the world against the men (the general ironic predicaments he is in) and the irony of man against the world (the solution avaible to him through irony).
\end{abstract}

Para Muecke, ambas perspectivas conforman una tensión dialéctica con dos polos interdependientes: por una parte, la ironía del hombre contra el mundo y, por otra, la ironía contra el hombre. El arte usará la ironía para recuperar la realidad con una ideología progresiva y con un espíritu crítico que, según él, está ligado a la filosofía postkantiana. Todo ello anticipa la representación en la representación y cita a este propósito al propio Pirandello (1969: 165). Bajo esta perspectiva, la ironía aparece como una forma dinámica abierta, definida en la obra de F. Schlegel (1987: 72) como la oposición de elementos incompatibles que producirán un arte progresivo capaz de trascender el texto y crear un espacio artístico. El concepto, que nace de la reflexión sobre las dificultades interpretativas del filólogo, es identificado como extrema movilidad espiritual; la ironía, o forma de lo paradójico, tiene su propio terreno específico en la filosofía, no en la estética.

La ironía filosófica, después de la infuencia de Kierkegaard y Nietzsche, cambiará sustancialmente en el arte del siglo XX; continuará ocupando el centro de la producción literaria después del romanticismo, pero su función irá trasladándose progresivamente desde el intento de recuperación de la realidad objetiva hacia la superación del nihilismo a través de la aceptación de una realidad ambigua y contradictoria. Es entonces cuando reaparece con fuerza la potencia subversiva del cómico. La dimensión lúdica y deformante de la ironía será aprovechada para desvirtuar o dar relieve a las paradojas de los valores convencionales de una cultura en crisis. En este pasaje de lo decimonónico a lo moderno se acentúa el rechazo por la retórica, considerada entonces un anticuado corsé represor de las exigencias del arte nuevo, o un mero repertorio de 
ornamentos vacíos de significado. Por ejemplo, Pirandello (1986) identifica retórica con artificio; de ahí que en su teoría estética distinga entre los términos de ironía (=retórica) y humor. Este último es, para Pirandello, un concepto más complejo. Asume los métodos de la ironía pero dentro de una perspectiva filosófica capaz de superar la oposición entre idealidad y realidad a través de un ejercicio analítico.

En el contexto cultural de la época, determinado por un cambio de valores sociales y filosóficos, se cuestiona, por una parte, la función de la razón en el arte, a la vez que se desarrollan las disciplinas psicológicas que analizan el componente inconsciente de la inteligencia; y, por otra, la estabilidad de las estructuras genéricas y la jerarquía éticomoral de sus correspondientes héroes. Las formas cómicas, que hasta entonces habían sido marginales, empujan con fuerza en una pugna por apropiarse los recursos de la ironía, que había servido hasta ese momento a los géneros altos o sublimes. Quizá el resultado de esta presión haya influido, más de lo que pudiera pensarse, en la transformación de los géneros literarios actuales, y sobre todo en el desarrollo de la narrativa y el ensayo, puesto que uno de los rasgos de la codificación cómica es que evidencia los métodos de análisis empleados en la construcción de su propio discurso.

Para concluir, hay que destacar que los textos humorísticos poseen, junto a su función transgresora y su transversalidad, una técnica persuasiva específica que se apoya en el concepto moderno de ironía. La persuasión eficaz es, según Pavel (1985: 455), aquella que contagia o impone sus propios códigos de estimativa tanto mediante las formas microtextuales de expresividad retórico-literaria, como a través de una argumentación persuasiva macrotextual. Sin embargo, en el caso de los códigos cómicos se observa que el mayor foco de interés del emisor no es imponer o transmitir un valor ético (Perelman y OlbrechtTyteca, 1989: 132-135), sino varios valores contrapuestos. Lo que realmente interesa al emisor es la complicidad con el receptor por lo que respecta al método de la argumentación, con el fin de conseguir la implicación crítica del receptor en el proceso de representación. Dejar abierta la interpretación del ámbito estimativo, en pos de una autorrefencialidad de las estructuras lógicas utilizadas en la argumentación, creo que tiene un alcance mucho mayor que el de la subversión de una lógica instituida; presupone la inestabilidad virtual de cualquier orden racional, así como la creatividad de la crítica en la ficción, lo que sin duda se refleja en la infiltración del ensayismo en todas las formas literarias contemporáneas. 


\section{Referencias bibliográficas}

Aristóteles, (1982 [1974]). Poetica [Ed. V. García Yebra.] Madrid: Gredos. AULLÓN DE HARO, P. (1991). «El humor en la poesía moderna contemporánea». Diálogos Hispánicos de Amsterdam 10, 201-208.

BACHTIN, M. (1974). La cultura popular en la Edad Media y el Renacimiento. Barcelona: Barral.

BAudelaire, CH. (1932 [1855]). «De l'essence du rire et généralement du comique dans les arts plastiques». OEuvres [Ed. Y. G. Le Dantec.], 170178. París: Gallimard.

BENJAMIN, W. (1980). Iluminaciones. Madrid: Taurus.

BERGSON, H. (1956). La risa. Barcelona: Plaza y Janés.

BоOTH, W. (1986). La retórica de la ironía. Madrid: Taurus.

Borsellino, N. (1989). La tradizione del comico. Milán: Garzanti.

BotTIROLI, G. (1990). «Bachtin, la parodia del possibile». Strumenti Critici $63,147-165$.

Celli, G. (1982). La scienza del comico. Bolonia: V. Eco Calderini.

El Outmani, I. (1995). Anatomies of subversion in Arabic and Spanish Literatures. Univ. Amsterdam. Tesis doctoral.

ENGLISH, J.F. (1986). «The laughing reader: a new direction for studies of the comic». Genre 19: 2, 129-154.

FerRoni, G. (1983). L'ambiguità del comico. Palermo: Sellerio.

GARCía BERRIO, A. (1994). Teoría de la literatura. Madrid: Cátedra.

GRUBER, W. E. (1981). «The wild men of comedy: trasformations in the comic hero from Aristofanes to Pirandello». Genre 14, 207-227.

Huerta Calvo, J. (1989). Formas carnavalescas en el arte y en la literatura. Barcelona: Serval.

HuIzINGA, J. (1968). Homo ludens. Madrid: Alianza.

HUTCHEON, L. (1981). «Ironie, satire, parodie. Une approche pragmatique». Poétique 45, 140-155.

- (1984). «Authorized trasgession: The Paradox of Parody». En Le signe à la porte. Vers une théorie de la parodie, Peter Lang (ed.), 13-26. New York-Berne-Frankfurt-Main: Lang.

JANKÉLÉVITCH, W. (1983 [1936]). La ironía. Madrid: Taurus.

Kerbrat-Orecchioni, C. (1980). «L'ironie comme troppe». Poétique 41, 108-127.

Knox, N. (1961). The word 'irony' and its context, 1500-1755. Durham: Duke University Press.

LAUSBERG, H. (1966). Manual de retórica literaria. Madrid: Gredos.

MUECKE, D.C. (1969). The compass of irony. Londres: Methuen \& Co.

NiETZSCHE, F. (1982 [1885]). Así habló Zarathustra. Barcelona: Orbis.

ORTEGA Y GASSET, J. (ed. 1993). Obras completas III. Madrid: Alianza.

Pavel, T.G. (1985). «Le déploiement de l'intrigue». Poétique 64, 455-462. 
Perelman, CH. y Olbrechts-TyteCA, L. (1989 [1952]). Tratado de argumentación. Madrid: Gredos.

Pirandello, L. (1986 [1908]). L'Umorismo. Milán: Mondadori.

Platón (1992). Diálogos. Madrid: Gredos.

Paulhan, F. G. (1914 [1909]). La morale de l'ironie. París: F. Alcan.

RIFFATERRE, M. (1976). Ensayos de estilística estructural. Barcelona: Seix Barral.

SCHELER, M. (1929). «El puesto del hombre en el Cosmos». Revista de Occidente 76-77.

SCHLEGEL, F. (1987). «Fragmentos del Lyceum». En Fragmentos para una teoría romántica del arte, AA.VV., 70-79. Madrid: Tecnos. 